\title{
Reconstruction of the Theory of Administrative Rule of Law in the Era of Artificial Intelligence
}

\author{
Zhiqing Wang \\ Wuhan University of Technology \\ Wuhan, China
}

\begin{abstract}
The progress of artificial intelligence technology has brought great changes to human social life, and has entered the age of artificial intelligence since then. From the era of artificial intelligence and the innovation of the theory of administrative rule of law, the traditional theory of administrative rule of law presents a stiff trend, and the new characteristics of the new era of efficiency orientation, procedural and participalism will profoundly cause the reform of the theory of administrative rule of law. Based on the background of the era of artificial intelligence, this paper puts forward the new connotation of the theory of administrative rule of law, trying to open up a new field of legal research and finally accept the double test of theory and practice.
\end{abstract}

Keywords-artificial intelligence; administrative rule by law; procedural doctrine

\section{INTRODUCTION}

In twenty-first Century, accelerating the development of human civilization and reconstructing the three scientific and technological innovations of the social organization structure: the Internet, large data and artificial intelligence. Today, artificial intelligence has become the power point of a new round of technological revolution and industrial revolution in the world. Artificial intelligence is a branch of computer science that studies and develops theories, methods, technologies and application systems for simulating, extending and expanding human intelligence. As far as professional research is concerned, there is no consensus on the definition of AI. "Computer and intelligence", called artificial intelligence, shows that "it's not the ability of the machine to imitate the human thinking process, but the ability to repeat the human behavior of human thinking," and John Mika tin, the author of the concept of modern artificial intelligence, says, "intelligence is about achieving a certain goal." The mechanism of action can be achieved by imitating human behavior, or by using any way to create a behavioral mechanism. Based on the methodology of the research of instrumentalism, we can give a definition of artificial intelligence, which is supported by modern algorithms, with large-scale historical data, and then forms the thinking activities of perception, learning, reasoning and decision making, and can complete the computing system of corresponding behavior according to certain instructions. Accordingly, the frontier science of artificial intelligence will change and even completely subvert all aspects of human social life, and the integration of artificial intelligence and legal knowledge will open up a new field of legal research and become a new academic growth point in the study of law.

In July 2017, the new generation of artificial intelligence development plan issued by the State Council referred to "promoting the intellectualization of social governance". The artificial intelligence platform suitable for government service and decision-making is developed, and the decision engine is developed for the open environment. It is popularized and applied in major strategic decisions, such as complex social problems, policy assessment, risk early warning, emergency disposal and so on. We should strengthen the integration of government information resources and accurate prediction of public demand, and smooth the interaction channels between the government and the public. In the nineteen major report of the party, general secretary $\mathrm{Xi}$ Jinping stressed that "strengthen the construction of social governance system, improve the social governance system of Party committee leadership, government responsibility, social coordination, public participation and the rule of law, and improve the socialization of social governance, the rule of law, intellectualization and specialization." In the field of judicial practice, the court of Shanghai emphasizes to seize the three new information signs and core technologies of large data, artificial intelligence and the Internet, to achieve a deep integration with the judicial operation mechanism, and to make artificial intelligence "walk into" the judicial field and create a "wisdom court".

Thus, the R \&amp; D and application of artificial intelligence technology is an important policy of the party and the state, which is not only related to national security, comprehensive strength and global competitiveness, but also is beneficial to risk control, social governance and judicial decision. The influence of the development and change of modern science and technology on the law and the legal system is omni-directional, but political and law should be the most impacted department law. The reason is that the administrative law involves a very wide range of fields and is very rich in content. It is different from other department laws. By combing the existing legal issues related to artificial intelligence, it is not difficult to find that the study of artificial intelligence is focused on civil law, criminal law and intellectual property, involving the legal qualification of robot, the copyright of artificial intelligence, the infringement of intellectual system and human privacy protection, problem of right and so on. Comparatively, there 
is not enough concern about the administrative law of AI, and little is known about the theoretical innovation of administrative law. Based on the theory of administrative rule of law, this paper attempts to explore the new connotation of the theory of administrative rule of law in the development of artificial intelligence at the theoretical level. As for the administrative rule of law theory, there is no immutable meaning. In the context of artificial intelligence, the traditional administrative rule of law theory has shown a certain lag and stiffness, and with the change of the times and the test of practice, it is not only necessary but also innovative to reinterpret the theory of administrative rule of law and give its time connotation.

\section{THE MEANING OF THE THEORY OF ADMINISTRATIVE RULE OF LAW}

The theory of administrative rule of law is regarded as the common theoretical source of administrative law in various countries. France, known as the mother country of the administrative law, believes that the administrative rule of law is the main content of the rule of law. It has four meanings: first, the administrative act must have the legal basis; the two is that the administrative act must conform to the law; the three is that the administrative organs must take action to ensure the implementation of the legal norms; four is the illegal act of sanction. Also in Britain, the liberal thought represented by daisy in the late nineteenth Century thought that the rule of law had three meanings: the government had no tyrannical discretion; the law was equal; the rights of citizens were not derived from the constitution, but were formed by the cases of the ordinary courts. Daisy's understanding of the rule of law in Britain does not conform to the reality of modern British administrative law. He does not expect that the rule of law today is not only the government's no arbitrary discretion, but that the government's laws must conform to modern human rights standards and can promote the economic and social rights of all the citizens of the society; Legal equality does not mean that the public and private laws of the United Kingdom are not divided, under the jurisdiction of the same court, and the same legal principles are applied; moreover, the rights of British citizens are derived from the results of the court's judgment, but it does not prove that the constitutional guarantee is undesirable. It is generally believed that the modern British rule of law theory includes: all activities of the government must abide by the law; the principle of rule of law is not limited to the principle of legality; the principle of rule of law indicates the protection of the law, and the principle of rule of law indicates that the law has no favoritism between the government and the citizens. In the United States, the rule of law is called the supreme principle of law, consisting of three basic factors, namely, basic rights, legitimate legal procedures and institutions that guarantee the authority of law. Although different countries have different understanding of the rule of law, they all permeate the common spirit of "rule of law", "rule of law", "administrative rule of law" and so on, which does not affect the dominating effect of the theory of rule of law on the administrative law of various countries.
What is the meaning of administrative rule of law in China? What kind of rule of law is depicted? Generally, the rule of law after the rule of law or the rule of law behind the rule of law in the rule of law to follow the exogenous evolution model, that is, by transplant or learn from the theory and practice of western countries under the rule of law, design the rules of the country to promote social change. China's administrative rule of law is the same, but there is a different understanding of the theory of administrative rule of law in China. A point of view is an analysis of the factors that constitute the administrative rule of law. For example, Mr. Luo Haocai summed up the basic principles of administrative law as the principles of administrative rule of law, and concretely divided them into principles of administrative legality and administrative rationality. Professor Jiang Mingan believes that the principles of administrative rule of law in China include "administration according to law", "administration by law" and "unity of rights and responsibilities". Professor He Haibo summed up the four essential elements of the administrative rule of law: one is that the administrative power is limited by the law; the two is the rules of the law; the three is that the government must abide by the law; and the four is the administrative dispute by the neutral institution. The other is a reference to the "outline of the full promotion of administrative implementation in accordance with the law" implemented by the State Council in 2004, indicating that the legal administration requires legal administration, reasonable administration, proper procedures, efficient convenience, honesty and trustworthiness and unity of power and responsibility. It can be seen that there are different views on the specific connotation of the administrative rule of law in the theoretical circle, and the six basic principles stipulated in the most representative official documents are the constituent elements of the administrative rule of law theory, that is, the legal administration, the reasonable administration, the proper procedure, the efficient convenience of the people, the honesty and the unity of power and responsibility together constitute the administrative rule of law.

\section{THE CHARACTERISTICS OF THE ADMINISTRATIVE RULE OF LAW IN THE ERA OF ARTIFICIAL INTELLIGENCE}

\section{A. Efficiency Oriented}

In the era of AI, the problem of massive data processing and decision is solved. The development and popularization of the Internet has widened the interaction boundary of the network society and created a huge data resource. How to deal with the massive data has become a problem to be solved urgently. Therefore, artificial intelligence (AI) arises at the historic moment, based on large data, and through its super computing power, it can process a lot of information quickly, complete the process of analyzing, processing and reproducing historical data, and generating all kinds of materials set up by the program operation. In a word, the ability of artificial intelligence in three levels of information collection and screening, recognition and response and independent judgment and decision will profoundly affect the content and form of administrative activities. This is an 
unparalleled data processing and decision-making work for any human and organization.

Improving administrative efficiency is the unremitting pursuit of administrative activities. Restricted by the budget and resources, the administrative subject is limited in the size and quantity of the personnel, and the demand for modern public management and service is increasingly complex. The development of administrative activities is faced with the lack of human resources and low administrative efficiency, and the efficiency oriented artificial intelligence will greatly alleviate this dilemma. At present, artificial intelligence has been used in the fields of finance, medical treatment, education, security and other fields. It can be applied to information collection, administrative process and administrative consultation response in the administrative field. It has replaced the traditional human resource input and improved the low efficiency of the shortage of human resources. Taking administrative litigation as an example, the fifty-first article of the "administrative procedure law" amended in May 1, 2015 stipulates three cases for registration of cases; the third paragraph stipulates that the contents of the prosecution form are deficient or have other mistakes. The amendment of this Law marks the transition from the censorship to the registration system in the administrative proceedings in China, on the one hand, the litigant rights of the parties are guaranteed by law; on the other hand, our country's pursuit of efficient administrative efficiency is reflected. It can be conceived that artificial intelligence can be used in administrative litigation on the level of filing a case, which can effectively identify the prosecution conditions of the prosecution, omit the redundant links in the judicial review process, complete the process of the document circulation with the speed of far exceeding manpower, and inform the prosecutor of the result of the ruling, and greatly improve the administrative efficiency.

\section{B. Fair and Justice}

As for the application of artificial intelligence in the administration, fair guidance is another important feature, which benefits from the ability of artificial intelligence in decision-making and corresponding behavior. By designing the reasoning mode of artificial intelligence, it can imitate the logic path of human reasoning, avoid all kinds of deviations and falsehood in human cognition, and make the decision of the administration more rational and objective. At this level, the use of automatic driving is the most widely used. Intelligent driving system, such as navigation system, sensor system, intelligent perception algorithm and vehicle control system, can determine the optimal driving route independently according to the changes of external environment conditions, so as to realize "artificial intelligence + unmanned".

Of course, AI is also applied to judicial organs to promote judicial justice. Legal reasoning is a form of thinking used by legal persons to apply formal logic to dealing with cases. It is an important part of legal methods. Although legal reasoning follows a unified legal standard, legal workers are individuals with differences in the subject, and it is difficult to avoid the result of discrepancy within the scope of discretion. However, the application of artificial intelligence will overcome the irrational factors, provide a relatively unified standard of reasoning and evaluation criteria for judicial trial, and greatly reduce or even eliminate the phenomenon of "the different judgments of the same case" caused by the subjective difference. As far as it is concerned, artificial intelligence has not been widely used in the administrative field. It can draw lessons from its role in the judicial system, apply artificial intelligence to administrative decision-making, collect information in an allround way, consider relevant factors, ensure the accuracy of decision making, and improve the fairness of the decision of the administrative subject.

In the field of law, both efficiency and fairness are important legal values. The emphasis on fairness is long and long, which is regarded as the manifestation of the spirit of law, and has the supreme status, and the law itself is regarded as the incarnation of fair and justice. In the administrative field, because of the complexity of administrative management and service, the voice of improving the administrative efficiency is strong, and the promotion of efficiency is a simple standard which is easy to be quantified. In the past, the construction of administrative rule of law pays attention to the introduction of efficient convenience measures, and the fairness of administrative decision is omitted. The popularization and application of artificial intelligence can improve administrative efficiency while highlighting the fairness and rationality of administrative decision-making, and contribute to the realization of administrative rule of law.

\section{Procedural Doctrine}

Procedural doctrine means that the administrative process of the administrative system of a government should be made according to legal procedures, emphasizing the order, time, steps and ways of administrative and administrative acts that have already been legally effective, both of which are equal. It is a gradual development process to attach importance to administrative procedures. In the nineteenth Century, the administrative rule of law in the west only paid attention to the administrative act and ignored the administrative process. In twentieth Century, it was realized that the administrative rule of law should also pay attention to the management and service process of the administrative subject. In his book "the theory of justice", Rawls, the American political philosopher, mentions the core of modern programming: "one is that the rule of law requires and prohibits acts that people are reasonably expected to do or do not do. Two are those who make laws and give orders, and three are similar cases." The four is the rule that the law prohibits the non-crime and its implied requirements, "as Rawls shows, the procedure itself can be judged as the criterion of justice.

Although the eighty-ninth, 107th constitution of our country has a high degree of generality to the administrative power and its scope of administrative system in our country, the administrative system can exercise a very broad administrative power according to this, but the administrative 
system lacks obvious procedural tendencies. The "administrative procedure law" promulgated in 1990 is one of the three important elements of the legal procedure, which has formally established the important position of the administrative procedure law in the administrative rule of law of our country. However, the time of the past 30 years has passed, and the administrative procedural law of our country still has some hesitation on the issue of the legal codification. Under the background of the development of AI technology, can procedural doctrine become the feature of this era? The answer is yes. The development of artificial intelligence makes the administrative system more transparent and participatory, mobilizes the administrative relative's cooperation and participation in management and service, enhances the mutual communication, cooperation and trust between the administrative subjects, and compel the administrative process to conform to the legal order, time, steps and ways, and the administrative behavior is efficient. They are sex, openness, democracy and acceptability, while avoiding abuse of administrative rights.

\section{Expansion of the Object of Administrative Supervision}

The expansion of the subjectivity of artificial intelligence is another characteristic of the times. In the practice of human-computer interaction, the artificial intelligence can perform tasks by automatic cognition, decision and behavior, which makes the artificial intelligence show some "subjectivity" to a certain extent, but it needs to be explained that this "subjectivity" is purely functional imitative rather than conscious activity, so it is called "the quasi owner". Body nature. Then, what kind of legal problems will happen when artificial intelligence is applied to the administrative field?

First of all, it is clear that the current stage belongs to the application of the weak artificial intelligence, that is, the artificial intelligence is still the "auxiliary tool" of the administrative act, and there is no substantial difference from the traditional "product". Therefore, the artificial intelligence with a certain "subjectivity" will not be included in the category of the administrative subject, the administrative counterpart or the related person. It is still understood as an auxiliary tool of administrative activities. However, artificial intelligence can be the object of legal regulation. Unmanned vehicles may cause the following two problems: first, the access qualification of the traffic field. With the disappearance of the driver concept of the pilotless car driver, the object of administrative regulation has shifted from the vehicle driver to the intelligence of the unmanned vehicle; the two is the transfer of the center of gravity of the traffic supervision and the traffic safety as the target. The focus of management supervision is from the driver's safe driving skills and the safety performance of the car, which is transferred to the software and hardware system of emergency protection and accurate driving in the process of automatic driving. It is necessary to explain that, due to the traffic accidents caused by autopilot, there is no subjective "intentional" or "negligence", which lies in the correctness of the accident, and the subject of the ultimate responsibility is still the owner of the unmanned vehicle. In this way, the application of artificial intelligence in the administrative field will expand the object of administrative supervision, which is another characteristic of the era of artificial intelligence.

\section{THE TIME CONNOTATION OF THE THEORY OF ADMINISTRATIVE RULE OF LAW}

As mentioned in the previous article, the connotation of the theory of administrative rule of law will not be constant, but there are many factors influencing the spirit of its times. The background of science and technology is one of the key points. "The boundary between law and technology will be one of the fields of development in the future, and it must be paid close attention to". The promotion and application of artificial intelligence in the field of administrative law is to take it as an auxiliary tool for administrative activities, and think more about how the development of artificial intelligence will bring about the influence and change of the theory of administrative law.

\section{A. Best Administrative Principle}

1) The fossilization of "legal administration": The legality of administrative action has always been the focus of administrative law research. The relationship between "official and the people" in the administrative legal relationship determines the strong position of the administrative subject. "The theory of control" naturally becomes the starting point of the construction of all theories and systems. The principle of "legality" has become one of the principles of administrative law, and it is the primary principle that all administrative actions must follow. This principle pays attention to the legal regulation of administrative act. It requires the authority, basis and procedure of administrative power to be strictly limited in the scope of the law. It will recourse to the judicial organs for administrative relief to the unlawful administrative act, and the court will revoke the administrative act, confirm the law and other judgments to be corrected or remedied. However, this kind of judicial relief is to safeguard the administrative legitimacy in the form of case justice, and it is not the primary purpose of the administrative law to confirm the administrative law or to punish the responsible person, nor is it the most desired result of the administrative counterpart.

In addition, the "legitimacy" principle is also faced with two major problems: the single standard and the limitation of judicial supervision. The principle of "legality" is limited to examining whether the administrative power is legal or not, whether it is abused or not, it is the lowest level of law, and is helpless to different degrees of administrative action which lacks rationality and does not meet the requirements of the administrative economy. At the same time, the general standard of the judicial review of administrative acts is the standard of "legality". This "low level" standard makes it impossible for the court to give up the administrative act that is not reasonable. It is not difficult to find that in the face of the increasingly complex administrative activities and the continuous expansion of the right of discretion, the principle 
of "legitimacy" has shown a certain rigidity, and the academic and practical circles are gradually paying attention to the better administration more than "legal administration".

2) The possibility of "best administration" application: The best administrative theory means that in the administrative law, the administrative activities can reach the most appropriate, that is, the most consistent with the administrative purpose and the state of the administrative economy, which is rooted in many local conditions at that time. As mentioned above, the purpose of administrative activities is to improve the quality of administrative activities. The principle of "legality" is the minimum requirement for administrative acts. The best administrative principle is the highest standard. The question is whether the "best administration" is possible in the era of artificial intelligence.

In the traditional era, it is difficult for the administrative subject to provide public services and cooperation according to the personality and difference of the administrative relative, and it is easy to establish a personalized database of mass citizens on the basis of large data, and the administrative activities can not only be provided according to the individual data of the administrative relative. The personalized management can also allocate administrative resources timely and effectively. It can be said that AI technology provides the possibility for the realization of the best administration. As an auxiliary tool for administrative activities, artificial intelligence can decide the best action plan independently according to the changes of the external administrative environment, and this "best" is beyond the standard of "legitimacy", and it also enriches the connotation of reasonable administration to a great extent.

\section{B. The Principle of Justice and Efficiency}

1) Efficiency and justice: the value goal of the administrative procedure law: Efficiency and justice are a group of contradictions and unity of opposites. In the nineteenth Century, the western jurisprudence pursued individual freedom, thought that the value of the rule of law was fair, and in twentieth Century, due to the emergence of administrative services and cooperation, jurisprudence thought efficiency was its value orientation. Western scholars believe that "only efficient administration can provide more services for more people."

Efficiency and justice are paid attention to as the two value targets of administrative procedure law in our country. The reasons can be summarized as two aspects. First, the administrative power involves all aspects of social life, and the corresponding is a set of huge bureaucracy. How to improve the administration of the administrative organs to the social affairs is very important, It is considered that the administrative process should be an optimal management process, with a small social cost for a larger profit. Second, the expansion of the administrative power and the origin of the right of discretion increase the possibility of infringement on the rights and interests of the administrative relative, aggravate the inequality in the administrative legal relationship, and the administrative subject has extensive administrative and administrative measures, while the relative person is in a clear disadvantageous position, which provides a procedural protection for the rights and interests of the relative person. At least the impartiality of the administrative process is ensured. Because of the inherent requirements of these two aspects, efficiency and justice are the two major objectives of the administrative procedure.

2) Modern administration demands fairness and efficiency: Efficiency and justice in administrative procedures can be regarded as one of the basic elements of the theory of administrative rule of law in the era of AI. The development of modern administration, efficiency and justice are no longer a group of irreconcilable contradictions, with the progress of artificial intelligence technology, efficiency and justice are the characteristics of the times brought by science and technology, both can be realized and even achieve a perfect fit, and the principle of efficiency and justice is not only the value goal of the administrative procedure law only. At the same time, it is the new connotation of the modern administrative rule of law theory.

\section{The Principle of Auxiliary}

1) "Auxiliary" principle: "The outline of the comprehensive promotion of administration by law" issued by the State Council in 2004 emphasizes that "all citizens, legal persons and other organizations can solve them independently, the market competition mechanism can be regulated, and the business organizations or intermediaries can solve the problems through self-discipline. Besides the law, the administrative organs do not pass the line. "Political management to solve it. "According to this, some scholars have proposed that the administrative law of China should introduce the "auxiliary principle", strengthen the deficiency of the traditional principle and the principle of rationality, and embody the reform requirements of the administrative law and the combination of decentralization and management, and then promote the cooperation of public and private. In fact, many scholars in China have widely discussed the application of this principle on the issues of administrative payment, administrative system reform, individual and the relationship between the state and the society. The thirteenth article of the administrative licensing law, which was implemented in 2003, also embodies the principle of auxiliary.

2) The application of auxiliary principles: The auxiliary principle refers to the private or market business that can be solved by its own; if it cannot be solved, the government is responsible for it; when the lower government cannot be independent, it is provided by the superior government; the auxiliary behavior of the higher government cannot replace the self-help behavior of the lower government. Specifically, the auxiliary principle has two levels of goal orientation: one is to deal with the relationship between the private, the market and the government in the social governance; the two is to deal with the relationship between the central and 
local governments, or between the higher government and the lower government.

The artificial intelligence technology extends the scope of the ability of the administrative relative and the administrative subject, and the modern government should be the government of "less management and better management". The establishment of the auxiliary principle gives individuals and smaller lower organizations the priority of transaction processing, and the development of artificial intelligence ensures the technical means to exercise this right. The theory of administrative rule of law introduces auxiliary principles, fully coordinating the exertion of government functions and the initiative of autonomous autonomy.

\section{The Principle of Cooperation}

1) The meaning of the "cooperative" principle: Administrative cooperation is a practical and rational activity between administrative organs and citizens, legal persons or other organizations, including administrative cooperation in administrative legislation, administrative cooperation in administrative decisions and administrative cooperation in administrative law enforcement. Administrative cooperation should permeate all fields and links of administrative activities. It is determined by the relationship between the government and the government. It is also necessary for the specific relative to maintain its own rights. It is also required by the nature of cooperation. The premise of administrative cooperation is that the administrative counterpart must have equal and free cooperation rights, including participation, dialogue, consultation and other rights. Such cooperation rights must be realistic and realable, not just the concept or declaration form. Administrative cooperation must also be rational and orderly cooperation rather than irrational. In short, the purpose of administrative cooperation is to achieve the scientific and rational allocation of public administrative resources through cooperation.

2) "Cooperation" principle under artificial intelligence: One of the characteristics of the era of AI is participation, while modern administrative law is based on democratic administration and emphasizes the autonomy and participation of citizens. Therefore, the relationship between government and individuals in modern administrative law is a cooperative trust relationship, and the corresponding mode of public administration is cooperative administration. The development of artificial intelligence makes administrative cooperation a new mode of administrative law. In all aspects and links of administrative legislation, administrative decision and administrative law enforcement, there should be extensive participation of administrative relative, interested people, related interest groups and experts and scholars to publish opinions and views. The administrative organs should fully listen to their opinions, discuss with them, consult with them, and make a final decision on this basis. It can be said that the principle of cooperation embodies the concept of rule of law in the interaction of politics and society.

\section{CONCLUSION}

The application of artificial intelligence in the administrative field is only just started, and the innovation of the theory of administrative law has not yet been involved. From this point of view, this paper is forward-looking. Artificial intelligence technology will inevitably bring many characteristics of the times, such as efficiency oriented, procedural and participalism, and the application of practice will affect the innovation of the theoretical level. This paper puts forward the best administrative principle, the principle of fairness and efficiency, the principle of auxiliary and the principle of cooperation, just as "practice is the only one to test the truth." The "standard" and the concept of the concept of administrative rule of law must be verified through practical examination, which is the joint effort of the theoretical and practical circles.

\section{REFERENCES}

[1] Jia Kai, and Jiang Yuhao,'Three basic problems in the management of artificial intelligence: technical logic, risk challenge and public policy choice",China Administration, October 2017, pp. 40- 45.

[2] Wu Handong,'The system arrangement and legal regulation of the age of artificial intelligence",Legal Science, May 2017, pp.128 - 136.

[3] Wang Qian,'On the qualitative of the content of artificial intelligence in the copyright law”,Legal Science,May 2017, pp.148 - 155.

[4] Tian Yongjun," The reform of administrative law calls for "the best administration"",Northern Jurisprudence,January 2018 ,pp. 110 - 124.

[5] Wang Xixin,"The orientation of the value of administrative procedural law",Politics and Law, March 1995, pp.60 - 65 .

[6] Guan Baoying,'Interpretation of the spirit of the times in the administrative rule of law", Politics and Law, January 2017,pp.4660 .

[7] Ying Songnian,"the prospect of Chinese Administrative Procedure Law", Chinese law ,March 2010,pp.15 - 26. 